\title{
Phylogeny of the family Moraxellaceae by 165 rDNA sequence analysis, with special emphasis on differentiation of Moraxella species
}

\author{
Bertil Pettersson, ${ }^{1}$ Angeli Kodjo, ${ }^{2}$ Mostafa Ronaghi, ${ }^{1}$ Mathias Uhlén ${ }^{1}$ \\ and Tone Tønjum ${ }^{3} \dagger$
}

Author for correspondence: Tone Tønjum. Tel: +47228695 10. Fax: +4722869490. e-mail: tone.tonjum@rh.uio.no

\footnotetext{
1 Department of Biochemistry and Biotechnology, Royal Institute of Technology, S-10044 Stockholm, Sweden

2 Ecole Nationale Vétérinaire de Lyon, Lyon, France

3 Institute of Medical Microbiology, Department of Molecular Biology, University of Oslo. National Hospital, N-0027 Oslo, Norway
}

\begin{abstract}
Thirty-three strains previously classified into 11 species in the bacterial family Moraxellaceae were subjected to phylogenetic analysis based on 165 rRNA sequences. The family Moraxellaceae formed a distinct clade consisting of four phylogenetic groups as judged from branch lengths, bootstrap values and signature nucleotides. Group I contained the classical moraxellae and strains of the coccal moraxellae, previously known as Branhamella, with 165 rRNA similarity of $\geq 95 \%$. A further division of group I into five tentative clusters is discussed. Group II consisted of two strains representing Moraxella atlantae and Moraxella osloensis. These strains were only distantly related to each other $(93.4 \%)$ and also to the other members of the Moraxellaceae ( $\leq 93 \%)$. Therefore, reasons for reclassification of these species into separate and new genera are discussed. Group III harboured strains of the genus Psychrobacter and strain 752/52 of [Moraxel/a] pheny/pyruvica. This strain of [M.] phenylpyruvica formed an early branch from the group III line of descent. Interestingly, a distant relationship was found between Psychrobacter phenylpyruvicus strain ATCC 23333' (formerly classified as [M.] phenylpyruvica) and [M.] phenylpyruvica strain 752/52, exhibiting less than $96 \%$ nucleotide similarity between their 165 rRNA sequences. The establishment of a new genus for [M.] phenylpyruvica strain 752/52 is therefore suggested. Group IV contained only two strains of the genus Acinetobacter. Strategies for the development of diagnostic probes and distinctive sequences for 165 rRNA-based species-specific assays within group I are suggested. Although these findings add to the classificatory placements within the Moraxellaceae, analysis of a more comprehensive selection of strains is still needed to obtain a complete classification system within this family.
\end{abstract}

Keywords: Moraxella, 16S rDNA sequences, phylogeny, classification

\section{INTRODUCTION}

Several fastidious Gram-negative bacterial species, other than established human pathogens such as Neisseria meningitidis, Neisseria gonorrhoeae and Haemophilus influenzae, are emerging as being important

†Present address: Department of Microbiology and Immunology, University of Michigan Medical School, 5641 Medical Science Building II, Ann Arbor, MI 48109-0620, USA. Tel: +1 313647 6765. Fax: + 13137643562.

The GenBank accession numbers for the sequences reported in this paper are AF005160-AF005192. as causes of opportunistic infections, including species of the bacterial family Moraxellaceae. For example, all members of the classical moraxellae, that is Moraxella lacunata, Moraxella nonliquefaciens and Moraxella bovis, may cause eye infections $(7,9,25,45) . M$. nonliquefaciens, which may be part of the normal airway flora, has been found as a cause of septicaemia in leukaemic patients $(3,53)$. Moraxella (Branhamella) catarrhalis may cause eye, ear and sinus disease in children, a population displaying a high rate of colonization with this species $(14,15)$. This agent can also cause exacerbations of chronic bronchitis. 
Table 1. Bacterial strains included in the study

\begin{tabular}{|c|c|c|c|}
\hline Species/strain & Origin & Accession no. & Reference \\
\hline \multicolumn{4}{|l|}{ M. lacunata } \\
\hline TT25: ATCC $17967^{\mathrm{T}}$ & Eye infection & AF005160 & Henriksen (23) \\
\hline TT26: ATCC 17956 & Eye infection & AF005161 & Juni (34) \\
\hline TT27: E 7992 & Eye infection & AF005162 & Juni (34) \\
\hline TT28: 50141 & Conjunctivitis & AF005163 & Ringvold et al. (45) \\
\hline TT29: 50142 & Conjunctivitis & AF005164 & Ringvold et al. (45) \\
\hline TT41: E2371 & Conjunctivitis & AF005165 & Juni et al. (34) \\
\hline TT42: CDC9833 & Conjunctivitis & AF005166 & Tønjum $(5,52)$ \\
\hline TT53: E3808 & Conjunctivitis & AF005167 & Juni et al. (34) \\
\hline TT54: NCTC 7911 & Conjunctivitis & AF005169 & Bøvre (5) \\
\hline TT55: A947 & Conjunctivitis & AF005168 & Bøvre (5) \\
\hline TT56: ATCC 11748 & Conjunctivitis & AF005170 & Bøvre (5) \\
\hline TT57: $28419 / 84$ & Conjunctivitis & AF005171 & Bøvre (7) \\
\hline \multicolumn{4}{|l|}{ M. nonliquefaciens } \\
\hline TT38: NCTC 7784 & Nasopharynx & AF005172 & Bøvre (5) \\
\hline TT23: B2000 & Septicaemia & AF005173 & Tønjum et al. (53) \\
\hline TT24: $3179 / 66$ & Nasopharynx & AF005174 & Bøvre (5) \\
\hline TT33: $13385 / 62$ & Nasopharynx & AF005175 & Henriksen (23) \\
\hline TT34: P2581/88 & Septicaemia & AF005176 & Tønjum et al. (53) \\
\hline TT36: 2916/66 & Nasopharynx & AF005177 & Bøvre (5) \\
\hline TT37: B6270/90 & Nasopharynx & AF005178 & Tønjum et al. (53) \\
\hline TT39: $826 / 61$ & Nasopharynx & AF005179 & Henriksen \& Bøvre (24) \\
\hline TT43: $270 / 60$ & Nasopharynx & AF005180 & Henriksen \& Bøvre (24) \\
\hline TT44: $672 / 58$ & Nasopharynx & AF005181 & Henriksen \& Bøvre (24) \\
\hline \multicolumn{4}{|l|}{ M. bovis } \\
\hline TT21: ATCC $10900^{\mathrm{T}}$ & Bovine conjunctivitis & AF005182 & Hughes et al. (25) \\
\hline TT22: 5 & Bovine conjunctivitis & AF005183 & Bøvre (5) \\
\hline \multicolumn{4}{|l|}{ M. equi } \\
\hline TT31: $372 / 72=$ ATCC $25576^{\mathrm{T}}$ & Equine conjunctivitis & AF005184 & Hughes et al. (25) \\
\hline \multicolumn{4}{|l|}{ M. catarrhalis } \\
\hline TT9: Ne11 = ATCC $25238^{\mathrm{T}}$ & Bronchitis & AF005185 & Catlin (13) \\
\hline \multicolumn{4}{|l|}{ M. ovis } \\
\hline TT30: $199 / 55=$ ATCC $33078^{\mathrm{T}}$ & Ovine respiratory tract & AF005186 & Bøvre (6) \\
\hline \multicolumn{4}{|l|}{ M. caviae } \\
\hline TT47: CCUG $355^{T}$ & Pharynx, guinea pig & AF005187 & Enevold Falsen \\
\hline \multicolumn{4}{|l|}{ M. cuniculi } \\
\hline TT49: CCUG $2154^{\mathrm{T}}$ & Oral mucosa, rabbit & AF005188 & Berger et al. (56) \\
\hline TT50: CCUG 27179 & Pharynx, rabbit & AF005189 & Enevold Falsen \\
\hline \multicolumn{4}{|l|}{ M. osloensis } \\
\hline TT11: 5873 & Respiratory tract & AF005190 & Bøvre \& Henriksen (10) \\
\hline \multicolumn{4}{|l|}{ M. atlantae } \\
\hline TT12: CDC A1922 & Blood & AF005191 & Bøvre et al. (8) \\
\hline \multicolumn{4}{|l|}{ [M.] phenylpyruvica } \\
\hline TT10: $752 / 52$ & Spinal fluid & AF005192 & Bøvre \& Henriksen (10) \\
\hline
\end{tabular}

The classification systems for species of the Moraxellaceae are still incomprehensive and evolving. The genera currently belonging to the Moraxellaceae are Moraxella including the previous Branhamella, Acinetobacter and Psychrobacter as suggested by Rossau and co-workers (46). Genetic relationships between these species have previously been extensively studied by genetic transformation $(5,7-9,29-33,35)$. This method has added most valuable information to their genetic affinities when key conventional phenotypic characteristics could not distinguish between these different entities. The dependence of this method on natural competence for transformation and growth caused a need for other nucleic acid techniques. Some species of genus Moraxella, such as Moraxella atlantae, Moraxella osloensis and [M.] phenylpyruvica are so distantly related that they can be separated and thereby identified by DNA-DNA hybridization using total genomic probes (52). One exception to this finding is the group containing the classical mor- 
axellae. The species designated as $M$. lacunata unifies the previous $M$. liquefaciens and $M$. lacunata, based on observations of particularly close genetic affinities (5, $23,34,38$ ).

The taxonomic placements of the less related moraxellae such as $M$. osloensis, $M$. atlantae and [M.] phenylpyruvica are still not detailed, as they display weaker genetic affinities to the classical moraxellae by transformation $(8,10,11)$, also verified by biochemical characterization and rRNA hybridization $(46,54)$ as well as partial $16 \mathrm{~S}$ rDNA sequence analysis (17).

Sequence comparison of RNA genes of the ribosomal small subunit, 16S rDNA, is a powerful tool for phylogenetic analysis of bacterial species $(36,39,48$, 58). In this work we present nearly full-length primary structures of the 16S rRNA molecule from 33 strains previously classified into the genus Moraxella. The sequences were obtained by semi-automated solidphase rDNA sequencing $(26,27,40-43,57)$. The sequences were used to elucidate the relationships between species belonging to the Moraxellaceae. The results were compared with previous classification schemes based on conventional methods and other nucleic acid techniques. Our main goals were to determine the relationships within the classical moraxellae as well as deciphering the placements of more distantly related Moraxella species and other members of the family Moraxellaceae.

\section{METHODS}

Bacterial strains and growth conditions. The strains investigated in this study are listed in Table 1. Species assignment was based on previous studies by genetic transformation in our laboratory $(5-11,23,24,52$, unpublished data), and results from Juni and co-workers (29-34). $M$. lacunata strains E2371 and E7992 were generously supplied by Dr E.
Juni, University of Michigan, USA. Strains Moraxella cuniculi CCUG 2154 and Moraxella caviae CCUG 355 we gratefully received from Dr E. Falsen at the CCUG strain bank in Gothenburg, Sweden. Strains were grown on $5 \%$ human blood agar plates (Difco) and chocolate agar plates at $33{ }^{\circ} \mathrm{C}$ with $5 \% \mathrm{CO}_{2}$.

In vitro amplification and DNA sequencing of the 16S rRNA gene. The PCR reactions were performed in a semi-nested fashion with one of the primers biotinylated as described previously (41). The 16S rRNA genes were amplified directly from the bacterial genome with the primers detailed in Table 2. Immobilization of the biotinylated PCR products followed by strand separation and template preparation was performed with superparamagnetic beads, Dynabeads M280 Streptavidin (Dynal). The nucleotide sequences from both strands were determined by automated solid-phase DNA sequencing $(26,27,57)$ with the ALFexpress (Pharmacia Biotech) as described previously (40-43). The sequencing primers are listed in Table 2.

Analysis of the 16S rRNA gene sequences. The sequences determined in this work were edited manually and aligned with a selection of $16 \mathrm{~S}$ rRNA sequences from members of the beta and gamma subclasses of the Proteobacteria. These were retrieved from the sequence collection of the Ribosomal Database Project (37) and from GenBank. The secondary structure of the 16S rRNA molecule of the $r r n B$ operon of Escherichia coli $(4,22)$ was retrieved and used for proper identification of stem-loop regions in the alignment procedure. Non-resolved positions and gaps were removed prior to the phylogenetic analysis. Distance matrices were corrected for multiple base changes at single locations by the method of Jukes \& Cantor (28). Phylogenetic trees were constructed from evolutionary distance matrices by the neighbour-joining method of Saitou \& Nei (47) using NEIGHBOR, contained in the Phylogenetic Inference Package, PHYLIP 3.51c $(18,19)$. Parsimony analysis was performed by using DNAPARS. Maximum likelihood based phylogenies were constructed with the DNAML program. The results obtained by both NEIGHBOR and DNAPARS were subjected to

Table 2. Primers used for PCR and DNA sequencing of Moraxella species

\begin{tabular}{|c|c|c|c|c|}
\hline Primer* & Position $\dagger$ & Sequence & Application & Reference \\
\hline 607 & $11-35$ & 5'-USP-GTTTGATCYTRGYTCAGAWTGAACG-3' & PCR & This study \\
\hline 612 & $339-360$ & 5'-USP-CTCCTAYGGGAGGCWGCAGKGG-3' & PCR & This study \\
\hline $390 \mathrm{~B}$ & 939-917 & 5'-CTTGTGCGGGYYCCCGTCAATTC-3' & PCR & (40) \\
\hline $621 \mathrm{~B}$ & $1517-1494$ & 5'-RSP-CCSSTACGGITACCTTGTTACGAC- $3^{\prime}$ & PCR & This study \\
\hline USP & & 5'-CGTTGTAAAACGACGGCCAG-3' & Sequencing & (43) \\
\hline RSP & & 5'-CACAGGAAACAGCTATGACC-3' & Sequencing & (43) \\
\hline $631 \mathrm{C}$ & $535-519$ & $5^{\prime}$-ATTACCGCGGCKGCTG-3' & Sequencing & This study \\
\hline $538 \mathrm{C}$ & $800-818$ & 5'-GTAGTCCACGCCGTAAACG-3' & Sequencing & (43) \\
\hline $390 \mathrm{C}$ & 939-917 & 5'-CTTGTGCGGGYYCCCGTCAATTC- $3^{\prime}$ & Sequencing & (43) \\
\hline $624 \mathrm{C}$ & $1237-1220$ & 5'-GTAGYAYGTGTGWAGCCC-3' & Sequencing & This study \\
\hline $623 \mathrm{C}$ & $1184-1200$ & 5'-GGGGATGATGTCAARTC-3' & Sequencing & This study \\
\hline
\end{tabular}

* $\mathrm{B}$ and $\mathrm{C}$ indicate that a biotin or an indodicarbocyanine (Cy5) dye, respectively, are coupled to the oligonucleotide.

$\dagger$ Numbers are according to the E. coli sequence (4).

$\ddagger$ USP and RSP means that the primer has a handle at the 5 -end with the sequence of the universal sequencing primer or the reverse sequencing primer. W, R, K, S and Y denote degenerated positions according to the single-letter code proposed by the Nomenclature Committee of the International Union of Biochemistry. An 'I' indicates that the primers have been synthesized with an inosine residue in the actual position. 
bootstrap analysis by using SEQBOOT in sets of 500 resamplings. The CONSENSE program was used for the subsequent computerization of majority-rule and strict consensus trees from the user trees.

Nucleotide sequence accession numbers. The sequences of the 16S rRNA genes from the Moraxella species and strains investigated in this work have the GenBank accession numbers listed in Table 1. The GenBank accession numbers for the 16S rRNA sequences of the reference strains used for comparison in this study are as follows: Acinetobacter calcoaceticus ATCC 11336, M34139 (58); Acinetobacter lwoffi ATCC 17925, U10875 (58); Aeromonas hydrophila ATCC 7966 ${ }^{\mathrm{T}}$, X60404 (38); Alcaligenes faecalis $\mathrm{ATCC}^{\mathrm{T}}$, M22508 (16); Cardiobacterium hominis ATCC 15826 ${ }^{\mathrm{T}}$, M35014 (16); Escherichia coli, J01695 (4); Haemophilus influenzae ATCC $33391^{\mathrm{T}}$, M59433 (16); Neisseria animalis ATCC 19573, L06172 (17); Oceanospirillum linum ATCC $11336^{\mathrm{T}}$, M22365; Pseudomonas aeruginosa ATCC 25330, M34133 (58); Psychrobacter immobilis ATCC 43116 ${ }^{\mathrm{T}}$, U39399 (2); Psychrobacter phenylpyruvicus ATCC 23333' U46144 (2).

\section{RESULTS AND DISCUSSION}

\section{Nucleotide sequence determination of the 16S rRNA gene}

Direct solid-phase DNA sequencing resulted in an unambiguous determination of almost complete ( $>95 \%$ ) sequences from the 16S rRNA genes of 34 strains from 11 recognized species of Moraxellaceae listed in Table 1. Both strands were sequenced to obtain accurate data. The obtained sequences were 1444-1451 nucleotides long, depending on the strain investigated. Polymorphic positions due to nucleotide differences between the rRNA genes at certain positions were not observed as was recently reported for certain strains of mycoplasmas and bacilli (40-43). This may indicate that either only one 16S rRNA gene is present in Moraxella species, that intrastrain variability of the nucleotide composition between the $16 \mathrm{~S}$ rRNA genes does not exist or that the potentially multiple 16S rRNA genes are identical.

\section{Phylogenetic position of the family Moraxellaceae}

Sequence information of the 16S rRNA genes from members of the family Moraxellaceae and selected relatives of the Proteobacteria $(37,49)$ was used to place the accommodated genera of Moraxellaceae (46) within the Proteobacteria. For this purpose, a distance matrix was calculated for 10 species representing the Moraxellaceae and eight relatives in the beta and gamma lineages of the Proteobacteria. The matrix was calculated from a sequence alignment consisting of the 1355 positions for which data were present. An evolutionary distance tree derived from the distance data by using the neighbour-joining method (47) is

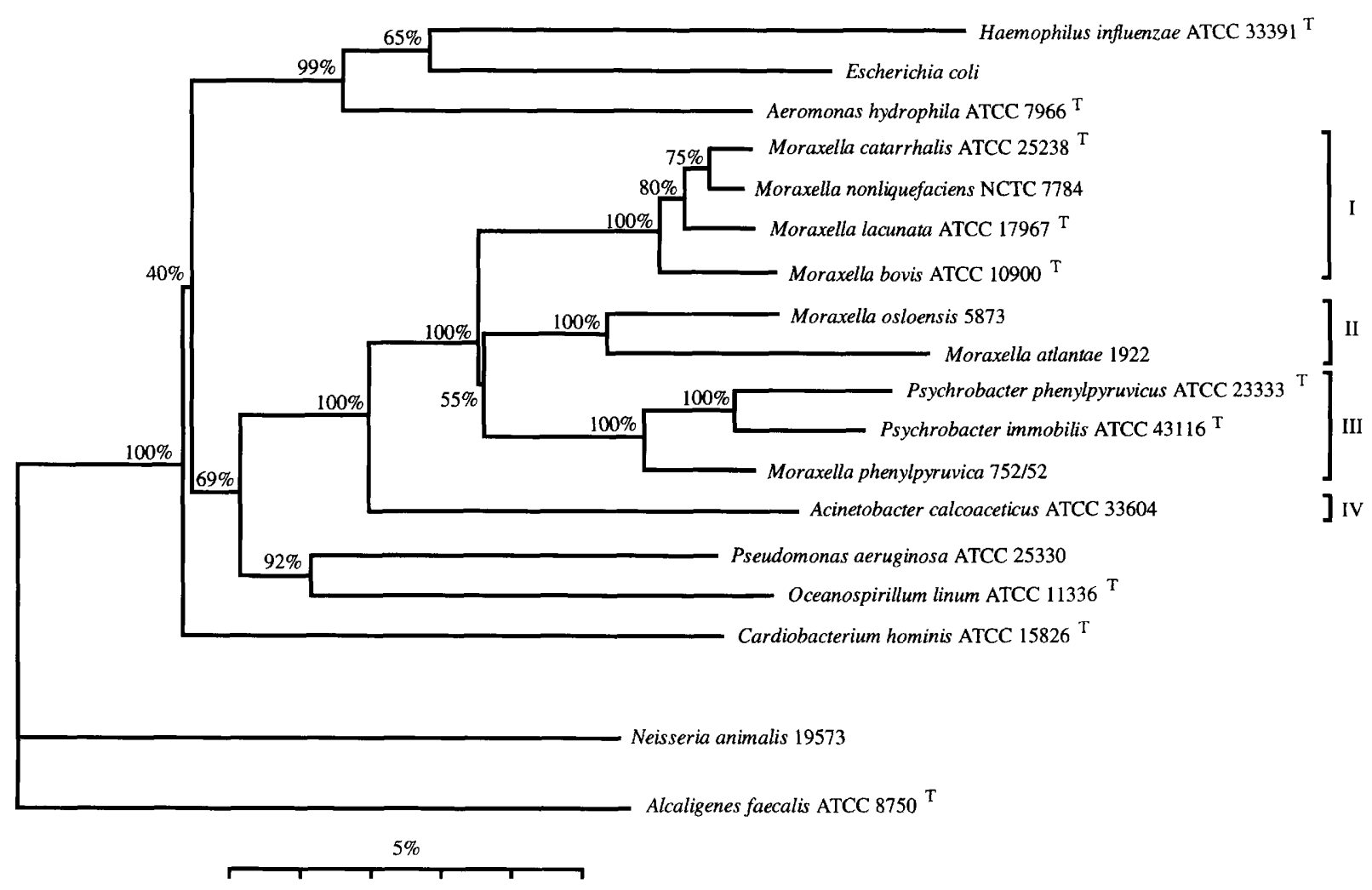

Fig. 1. Phylogenetic tree based on distance matrix analysis of 1355 positions in the $16 \mathrm{~S}$ rRNA genes from selected members of Moraxellaceae, of which some were sequenced in this work, and relatives of the Proteobacteria. Alcaligenes faecalis was used as the out-group. Bootstrap percentage values obtained from 500 resamplings of the data set are given at the nodes. The tree reveals four distinct clades within the family Moraxellaceae, denoted groups I-IV. 
Table 3. Signature nucleotide positions of the Moraxellaceae

The analysis included 16S rRNA sequences of the Moraxellaceae family generated in this study and deposited in GenBank.

\begin{tabular}{|c|c|c|c|}
\hline $\begin{array}{l}\text { Position of base } \\
\text { or pair* }\end{array}$ & $\begin{array}{l}\text { Moraxellaceae } \\
\text { family }\end{array}$ & Bacteria ${ }^{\dagger}$ & Exceptions (phylum, genus or other phylogenetic group) $\ddagger$ \\
\hline $124 \cdot 237$ & $\mathrm{U} \cdot \mathrm{A}$ & $\mathrm{G} \cdot \mathrm{C}$ & $\begin{array}{l}\mathrm{U} \cdot \mathrm{A}: \text { Colwellia assemblage, Alteromonas group, HP } \\
\mathrm{U} \cdot \mathrm{U}: \text { Telluria }\end{array}$ \\
\hline 423 & $\mathrm{U}$ & G§ & $\mathrm{U}:$ Mycoplasma pneumoniae group (some) \\
\hline & & $\begin{array}{l}\mathrm{G} \|: P s y c h(2) \\
\mathrm{A} \|: M . \text { atl }\end{array}$ & A : STB subdivision \\
\hline 440 & A & $\mathrm{U}, \mathrm{C}$ & $\begin{array}{l}\text { A: Geotoga, Petrotoga, Thermus, Deinococcus, Serpulina, } \\
\text { Leptospira subdivision, Pseudomonas sub-group, } \\
\text { Francisella sub-group, Clostridium thermocellum sub- } \\
\text { group, Acetogenium sub-group, thermophilic genera }\end{array}$ \\
\hline $514 \cdot 537$ & $\mathrm{U} \cdot \mathrm{A}$ & $C \cdot G$ & $\begin{array}{l}\mathrm{U} \cdot \mathrm{A}: \text { Chloroflexus subdivision (2), Leptospirillum group, } \\
\text { green sulfur bacteria, Holospora, Oceanospirillum } \\
\text { assemblage (2), Pseudomonas sub-group (most), } \\
\text { Myxobacteria, Peptococcus, mycoplasmas and relatives } \\
\text { (most) } \\
\text { U.G: Verrucomicrobium, Ehrlichia (few) }\end{array}$ \\
\hline 1156 & $\mathrm{U}$ & G & $\begin{array}{l}\mathrm{U} \text { : Prevotella (some), Flexistipes, Caulobacter (some), } \delta \text { - } \\
\text { and } \varepsilon \text {-purple ( } 7 \text { ), Fusobacterium (most), } \\
\text { Peptostreptococcus (some), Mycoplasma (some) }\end{array}$ \\
\hline 1275 & $\mathrm{U}$ & A & $\begin{array}{l}\text { U: Herpetosiphon, } \alpha \text { - and } \delta \text {-purple (11), Thiothrix nivea } \\
\text { sub-group (most), Gram-positive phylum (10) }\end{array}$ \\
\hline
\end{tabular}

* Nucleotide positions are according to the E. coli numbering (4).

$\dagger$ Dominant base or pair in the corresponding position(s) of (eu)bacteria.

\$ The number of sequences in which the actual residue is found is in parentheses. Groups and sub-groups are according to the nomenclature used by the Ribosomal Database Project (RDP) (37). Abbreviations: STB, Spirochaeta-Treponema-Borrelia subdivision; HP, Haemophilus-Pasteurella group; $\alpha, \delta$ and $\varepsilon$, alpha, delta and epsilon subdivisions, respectively, of the purple bacteria (Proteobacteria).

$\S$ Many eubacteria truncate this position.

$\|$ A guanine is present in the actual position in 2 of the $16 \mathrm{~S}$ rRNA sequences of Psychrobacter and an adenine is present in the sequence of $M$. atlantae.

presented in Fig. 1. Bootstrap percentage values as obtained from 500 resamplings of the data set are given at the nodes of the tree. Alcaligenes faecalis served as an outgroup. The phylogenetic tree showed that the members of the family Moraxellaceae constituted a monophyletic taxon forming a distinct line of descent within the gamma subclass of the Proteobacteria (Fig. 1). Bacterial families closely related to the Moraxellaceae are the Aeromonadaceae and the Pseudomonas sub-group. Bootstrap analysis and the obtained branch lengths indicated that the Moraxellaceae branch was phylogenetically stable. Furthermore, the branch of the Moraxellaceae was supported by signature nucleotide positions (Table 3 ). Signature nucleotides in this context are nucleotide residues explicitly found in positions within the sequence where the base present differs from that found in the majority of the other (eu)bacteria. Moreover, the signatures may be useful for the development of diagnostic probes for rapid detection of members of the family Moraxellaceae. One suitable motif is the presence of the nucleotides $\mathrm{U}$ and $\mathrm{A}$ in positions 514 and 537, which is covered by the highly conserved eubacterial oligonucleotide UGUGCCAGCAGCCGCGGUAAUACA, of which over 3000 examples are known. As noted in Table 3, this target coincides only with members of mycoplasmas and relatives, Leptospirillum group, green sulfur bacteria, Pseudomonas sub-group and Myxobacteria.

\section{Phylogenetic groups within the Moraxellaceae}

The Moraxellaceae branched into four major lineages designated groups I, II, III and IV (Fig. 1). A tree was also constructed by including all currently known species belonging to Moraxellaceae of which $16 \mathrm{~S}$ rRNA sequence data could be retrieved (not shown). The additional species and strains belonging to the Moraxellaceae could be assigned to any of the four clades, without significant destabilization of the nodes of groups I-IV. Therefore, the reduced tree presented in Fig. 1 representatively describes the phylogeny of 


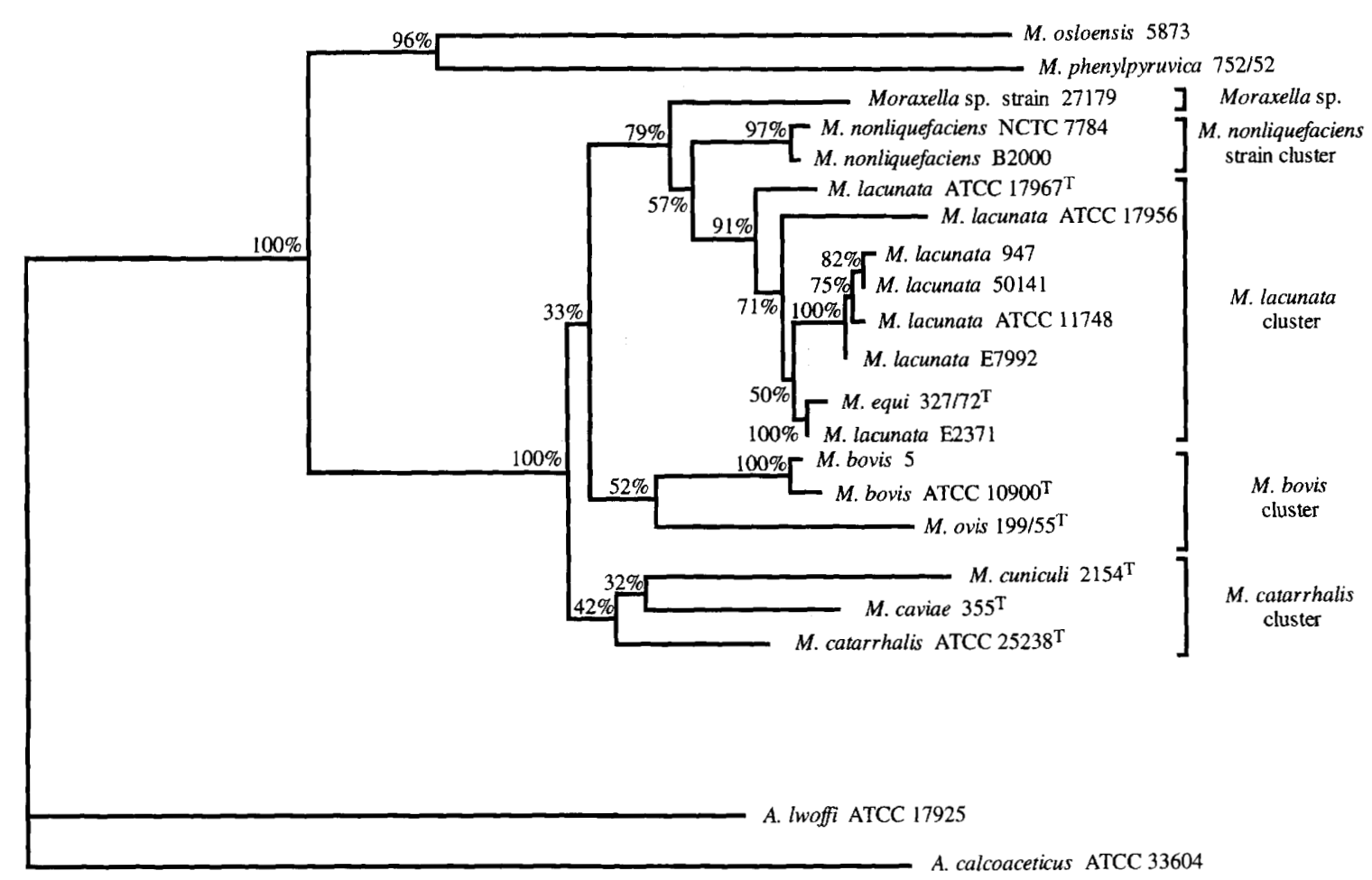

$1 \%$

Fig. 2. Phylogenetic tree based on distance matrix analysis of 1440 positions in the $16 \mathrm{~S}$ rRNA genes of the moraxellae sequenced in this work belonging to group 1 and selected members of the family Moraxellaceae. Acinetobacter calcoaceticus was used as the out-group. Bootstrap percentage values obtained from 500 resamplings of the data set are given at the nodes. The tree shows that the group I constitutes five clusters: the Moraxella sp. strain 27179 branch, the $M$. nonliquefaciens cluster, the $M$. lacunata cluster, the $M$. bovis cluster, and the $M$. catarrhalis cluster (see text for details).

the family Moraxellaceae. The four groups were considered to constitute reliable established phylogenetic units as judged from the percentage values obtained by bootstrap analysis (Fig. 1) and the signature and unique nucleotide positions presented in Table 4. The characterization of unique nucleotide features was restricted to be valid for the members of the respective group within the Moraxellaceae. A nucleotide residue at a certain position was said to be unique when it held for all strains within one of the four groups with no exception among the strains of any other group. A weak node positioned at the branching point between groups II and III was observed due to a bootstrap percentage of only $55 \%$ and a short common ancestral branch for these groups. The instability of this point of bifurcation was also registered by maximum likelihood analysis, where group I swapped its position with that of group III. Therefore, we do not consider the branching order among groups I, II and III to be established with certainty. However, the base pair in position 317.336 showed the composition $\mathrm{C} \cdot \mathrm{G}$ which was in common for the group II lineage and the early branches of the group III lineage. The later branches of some of the Psychrobacter strains showed C.C in the actual base pair of the group III line of descent. The $\mathrm{C} \cdot \mathrm{G}$ base pair is only found in Aquifex (one example), Marinobacter (1 example), the Actinobacillus sub-group (few), the Halomonas sub-group (some), Spiroplasma (few) and in the Cardiobacterium group (two examples). Therefore, this base pair was regarded synapomorphous for the common branch of groups II and III. The tree in Fig. 1 is likely to reflect the most likely phylogenetic relationship between these two clades. Groups I and II consisted of species traditionally classified in the genus Moraxella, group I contained the classical moraxellae and the coccal moraxellae previously named Branhamella (13), while group II consisted of the two species $M$. atlantae and $M$. osloensis. Group III harboured strains of the genus Psychrobacter and a single strain of [M.] phenylpyruvica. Group IV contained two strains of the genus Acinetobacter, representing the species Acinetobacter calcoaceticus. The four phylogenetic groups were in agreement with those found by using DNA-rRNA hybridization to study the taxonomic relationships of the Moraxella and allied bacteria (46). The overall topology of the tree and positioning within the Moraxellaceae was also consistent with previous reports based on analysis of partial 16S rDNA sequences from a minor data set 
(17), as well as genetic transformation and hybridization $(5-11,46,52,53)$.

\section{Group I, including the genus Moraxella sensu stricto: the classical moraxellae and the coccal moraxellae}

The phylogeny of group I was further detailed by comparison of the 16S rRNA sequences of 31 strains from eight of the recognized species included in this group. Therefore, 16S rRNA nucleotide information from close relatives of $M$. lacunata and selected members of the family Moraxellaceae were aligned. Gaps were removed and the final alignment consisted of 1440 nucleotide positions. A distance matrix was calculated with $A$. calcoaceticus serving as an outgroup (not shown). The members of group I showed $\geqslant 95 \%$ similarity between their $16 \mathrm{~S}$ rRNA sequences. $M$. nonliquefaciens was represented by only two strains because of a high nucleotide similarity within this species. A phylogenetic tree derived from distance matrix data by using the neighbour-joining method (47) is shown in Fig. 2. Group I contained species of the type genus Moraxella, harbouring the classical moraxellae and the coccal moraxellae. Interestingly, this group contains both rod-shaped and coccal species tightly affined within one (sub) genus. The phylogenetic analysis (Fig. 2) revealed five clusters within group I. However, bootstrap analysis by resampling the data set 500 times showed a marked instability for some of the nodes due to low percentage values. This was also indicated by a slightly different branching order obtained with the maximum likelihood method (data not shown) but without altering the species composition of the clusters. A compilation of informative 16S rRNA nucleotide positions was performed to verify the clusters of group I (Table 5). Informative nucleotide positions were restricted to the clusters of group I and defined as sites in which all members of a cluster share a nucleotide residue at a certain position in the $16 \mathrm{~S}$ rRNA molecule which is not shared with any other member of the group I. The Moraxella sp. strain CCUG 27179 was excluded in the unique nucleotide analysis since this strain formed a single strain branch. The five clusters, denoted as the $M$. lacunata cluster, the $M$. nonliquefaciens cluster, the $M$. bovis cluster, the $M$. catarrhalis cluster, and the Moraxella sp. strain 27179 branch, could in most cases be characterized by informative 16S rRNA residues. Group I is concordant with the ' $M$. lacunata homology group' as described by Rosseau et al. (46).

\section{The $M$. lacunata cluster}

The $M$. lacunata cluster, encompassing 13 strains of which eight strains showed unique 16S rRNA sequences, was in part relatively heterogeneous with interstrain similarity values ranging from 98.4 to $99.9 \%$ between their 16S rRNA nucleotide sequences (data not shown). Nevertheless, all derived phylogenies resulted in one cluster with an early branch of the type strain ATCC $17967^{\mathrm{T}}$ of $M$. lacunata and with strain ATCC 17956 forming an intermediate position with a branch length more than twice of that of the sister strains (Fig. 2).

Interestingly, all $M$. lacunata strains belonging to the small colony variant of this species, previously designated 'group II' $(34,53)$ or $M$. lacunata subsp. lacunata $(5,23,34)$, clustered tightly together with a $\geqslant 99 \cdot 8 \%$ nucleotide similarity between their $16 \mathrm{~S}$ rRNA sequences. The high similarity was observed despite the fact that these strains originated from different geographic regions (53). In contrast, the large colony variant of $M$. lacunata, previously denoted 'group I' or $M$. lacunata subsp. liquefaciens $(5,34,53)$, was more heterogeneous and these strains fell more peripherally within the $M$. lacunata cluster. Thus, the $16 \mathrm{~S}$ rRNA is far more conserved among strains corresponding to the previous $M$. lacunata subsp. lacunata as compared with $M$. lacunata subsp. liquefaciens strains. Except for strain E7992 which grew with large colonies, a correlation between $16 \mathrm{~S}$ rRNA sequences and the two distinct groups of $M$. lacunata as determined by colony morphology studies, nutritional requirements, multilocus enzyme electrophoresis (MLEE), cell wall fatty acid patterns and auxotrophic donor transformation activities toward Moraxella bovis $(34,38,53)$ was found (Fig. 2).

Surprisingly, Moraxella equi strain $327 / 72^{\mathrm{T}}$ was contained within the $M$. lacunata cluster with a $16 \mathrm{~S}$ rRNA sequence similarity of $99.9 \%$ to $M$. lacunata strain E2371 (Fig. 2). Moreover, $M$. equi shared all the informative nucleotides with the other members of this cluster (Table 5). Thus, based on 16S rRNA sequence comparison $M$. equi should be included in the $M$. lacunata group II cluster. The relationship between $M$. equi and other classical moraxellae was analysed by phenotypic characterization, genetic transformation and DNA-DNA reassociation experiments. The results suggested that $M$. equi should be taxonomically placed as a close relative of $M$. bovis, DNA-DNA relatedness being $92 \%(5,53)$. A reassignment of $M$. equi as a non-haemolytic variant of $M$. bovis was also supported by data obtained from MLEE and genetic transformation experiments $(5,53)$. The $16 \mathrm{~S}$ rRNA sequences of $M$. equi and the two $M$. bovis strains included in this study showed only 96.8 and $97.0 \%$ nucleotide similarity (data not shown). The overall genomic DNA-DNA similarity between $M$. equi and $M$. lacunata subsp. lacunata (group II) was found to be $57-62 \%$ in a previous study (53). Although this value was not as low as expected for non-related strains, the genome of $M$. equi was significantly more homologous to that of $M$. bovis, which is most closely related to $M$. lacunata subsp. liquefaciens (group I). Thus, the placement of $M$. equi based on 16S rRNA comparison is contradictory to previous reports and the classification of $M$. equi remains unresolved. This might be one example of limited concordance between total genomic and ribosomal nucleic acid sequences within certain species $(20,50)$.

The members of the $M$. lacunata cluster studied in this work are characterized by the following oligonucleo- 
Table 4. Signature and unique nucleotide positions of the phylogenetic groups within the Moraxellaceae family defined in this study

Groups are according to those defined in this study. Group I, the 'classical moraxellae' and the coccoid moraxellae; group II, $M$. osloensis and M. atlantae; group III, [M.] phenylpyruvica and Psychrobacter; group IV, Acinetobacter. A signature nucleotide is a nucleotide residue explicitly found in a certain position within the sequence in all members of the actual group where the base present differs from that found in the majority of other (eu)bacteria. A unique nucleotide holds for all members of a certain group within the Moraxellaceae but the actual residue may be found in several other (eu)bacteria. Signature nucleotides are in bold and unique nucleotides are underlined.

\begin{tabular}{|c|c|c|c|c|c|}
\hline \multirow{2}{*}{$\begin{array}{l}\text { Position of base } \\
\text { or pair* }\end{array}$} & \multicolumn{5}{|c|}{ Base or base pair in group: } \\
\hline & $\mathbf{I}$ & II & III & IV & Exception(s) (phylum, genus or other phylogenetic group) $\dagger$ \\
\hline 121 & $\mathrm{U}$ & $\underline{\mathrm{C}}$ & $\mathrm{U}$ & $\mathrm{U}$ & No signature \\
\hline $123 \cdot 238$ & $\mathrm{C} \cdot \mathrm{G}$ & $\mathbf{U} \cdot \mathbf{A}$ & $\mathrm{C} \cdot \mathrm{G}$ & $\mathrm{C} \cdot \mathrm{G}$ & $\begin{array}{l}\text { U.A: Enterics and relatives, Cardiobacterium group (2), } \\
\text { Wolbachia, Neisseria group (most), Bordetella sub-group, } \\
\text { Methylophilus group, other purple (few) }\end{array}$ \\
\hline 150 & $\mathrm{U}$ & $\mathbf{U}$ & $\mathrm{U}$ & $\underline{\mathrm{C}}$ & No signature \\
\hline $198 \cdot 219$ & $\mathrm{G} \cdot \mathrm{C}$ & $\mathrm{G} \cdot \underline{\mathrm{U}}$ & $\mathrm{G} \cdot \mathrm{C}$ & $\mathrm{G} \cdot \mathrm{C}$ & No signature \\
\hline $257 \cdot 269$ & $\mathrm{G} \cdot \mathrm{U}$ & $\mathrm{G} \cdot \underline{\mathrm{C}}$ & $\mathrm{G} \cdot \mathrm{U}$ & $\mathrm{G} \cdot \mathrm{U}$ & No signature \\
\hline $289 \cdot 311$ & $\mathrm{G} \cdot \mathrm{C}$ & $\mathbf{A} \cdot \overline{\mathbf{U}}$ & $\mathrm{G} \cdot \mathrm{C}$ & $\mathrm{G} \cdot \mathrm{C}$ & $\begin{array}{l}\text { A.U: Saprospira group (some), Borrelia group, Spirillum, } \\
\text { Pseudomonas sub-group, Plesiomonas, Bdellovibrio, } \\
\text { Campylobacter and relatives, other purple (2) } \\
\text { G.U: Nanocystis, Actinomyces sub-group, Quinella, } \\
\text { Haloanaerobium } \\
\text { A.C: Coprococcus (1), Coprococcus cuprinolyticum sub- } \\
\text { group (2) }\end{array}$ \\
\hline $320 \cdot 333$ & $\mathrm{G} \cdot \mathrm{C}$ & $\underline{\mathrm{A}} \cdot \underline{\mathrm{U}}$ & $\begin{array}{l}\mathrm{U} \cdot \mathrm{C} \\
\mathrm{G} \cdot \mathrm{C}\end{array}$ & $\mathrm{G} \cdot \mathrm{C}$ & No signature \\
\hline 443.491 & $\underline{\mathrm{U}} \cdot \underline{\mathrm{A}}$ & $C \cdot G$ & $C \cdot G$ & $C \cdot G$ & No signature \\
\hline 445.489 & $\mathrm{G} \cdot \mathrm{C}$ & $G \cdot C$ & $G \cdot C$ & $\underline{\mathrm{A}} \cdot \underline{\mathrm{U}}$ & No signature \\
\hline $446 \cdot 488$ & $\mathrm{G} \cdot \mathrm{C}$ & $\mathrm{G} \cdot \mathrm{C}$ & $\underline{\mathrm{U}} \cdot \mathbf{G}$ & $\mathrm{G} \cdot \mathrm{C}$ & $\begin{array}{l}\text { G: Serpulina, Spirochaeta (some), Treponema, Vibrio group } \\
\text { (some), HP (some), Mycobacterium (most), Actinomyces } \\
\text { (most) }\end{array}$ \\
\hline$(475) \ddagger$ & - & - & - & $\mathbf{A}, \mathbf{U}$ & A, U: FCB (3) \\
\hline $478 \ddagger$ & $\underline{\mathrm{C}}$ & $\mathrm{G}, \mathrm{U}$ & G & $\mathrm{G}, \mathrm{U}$ & No signature \\
\hline $479 \ddagger$ & $\underline{C}$ & $\mathrm{G}, \mathrm{U}$ & $\underline{\mathrm{A}}$ & $\mathrm{U}$ & No signature \\
\hline 480 & $\mathrm{U}$ & A, U & $\mathrm{U}$ & G & $\begin{array}{l}\text { G: Francisella sub-group, Legionella sub-group, Halomonas } \\
\text { sub-group (some) }\end{array}$ \\
\hline 560 & A & A & A & U§ & $\begin{array}{l}\text { U: Brucella assemblage (some), Phyllobacterium, } \\
\text { Beijerinckia sub-group, Bartonella sub-group, Bdellovibrio } \\
\text { stolpii group (2) }\end{array}$ \\
\hline $580 \cdot 761$ & $\mathrm{C} \cdot \mathrm{G}$ & $\mathbf{U} \cdot \mathbf{A}$ & $\mathrm{C} \cdot \mathrm{G}$ & $C \cdot G$ & $\begin{array}{l}\text { U.A: Leptospirillum, } \alpha \text {-purple (1), } \beta \text {-purple (1), Spirochaetes } \\
\text { and relatives (few), Capnocytophaga (1), Alteromonas } \\
\text { group (some), Vibrio group, Desulfuromonas group, } \\
\text { Bdellovibrio bacteriovorus group, Myxobacteria, } \\
\text { Arcobacter, Nocardia, Gardnerella, Arthrobacter group } \\
\text { (few), Propionibacterium group (few), Clostridium } \\
\text { thermobutyricum sub-group, Epulopiscum, } \\
\text { Acidaminococcus, Mycoplasma hominis group (some) }\end{array}$ \\
\hline $592 \cdot 647$ & $\begin{array}{l}\mathrm{U} \cdot \mathrm{G}, \mathrm{U} \cdot \mathrm{A}, \\
\mathrm{A} \cdot \mathrm{U}, \mathrm{C} \cdot \mathrm{G}\end{array}$ & $\mathrm{A} \cdot \mathrm{U}$ & $\underline{\mathrm{G}} \cdot \mathrm{U}$ & $\begin{array}{l}\mathrm{U} \cdot \mathrm{G}, \\
\mathrm{A} \cdot \mathrm{U}\end{array}$ & No signature \\
\hline $593 \cdot 646$ & $\mathrm{U} \cdot \mathrm{G}$ & $\begin{array}{l}\mathrm{U} \cdot \mathrm{G}, \\
\mathrm{C} \cdot \mathrm{G}\end{array}$ & $\underline{\mathrm{A}} \cdot \underline{\mathrm{U}}$ & $U \cdot G$ & No signature \\
\hline $616 \cdot 624$ & $G \cdot C$ & $\mathrm{G} \cdot \mathrm{C}$ & $\mathrm{G} \cdot \mathrm{C}$ & $\underline{\mathrm{A}} \cdot \underline{\mathrm{U}}$ & No signatures \\
\hline 631 & $\mathrm{C}$ & $\mathrm{C}$ & C & $\underline{\mathrm{U}}$ & No signature \\
\hline $661 \cdot 744$ & $\mathrm{U} \cdot \mathrm{A}$ & $\mathrm{U} \cdot \mathrm{A}$ & $\mathrm{U} \cdot \mathrm{A}$ & $\underline{G} \cdot \underline{C}$ & No signature \\
\hline $771 \cdot 808$ & $\mathrm{G} \cdot \mathrm{C}$ & $\mathrm{G} \cdot \mathrm{C}$ & $\mathrm{G} \cdot \mathrm{C}$ & $\mathbf{A} \cdot \mathbf{U}$ & $\begin{array}{l}\mathrm{A} \cdot \mathrm{U}: \mathrm{Gr}-(7), \text { Arthrobacter (most), Corynebacterium, } \\
\text { Lactobacillus (most), Actinomyces group (most), } \\
\text { Actinopolyspora, other } \mathrm{Gr}+(15)\end{array}$ \\
\hline
\end{tabular}


Table 4 (cont.)

\begin{tabular}{|c|c|c|c|c|c|}
\hline \multirow{2}{*}{$\begin{array}{l}\text { Position of base } \\
\text { or pair* }\end{array}$} & \multicolumn{5}{|c|}{ Base or base pair in group: } \\
\hline & $\mathbf{I}$ & II & III & IV & Exception(s) (phylum, genus or other phylogenetic group) $\dagger$ \\
\hline $827 \| \cdot 873$ & $\mathrm{C} \cdot \mathrm{A}$ & $\mathrm{U} \cdot \mathrm{A}$ & $\mathrm{U} \cdot \mathrm{A}$ & $\mathrm{U} \cdot \mathrm{A}$ & $\begin{array}{l}\text { C: Prevotella, Leptospira, Rhodobacter group, } \\
\text { Bradyrhizobium sub-group, methylobacteria, other } \\
\text { (eu)bacteria ( } 7 \text { ) }\end{array}$ \\
\hline $1006 \cdot 1023$ & $\mathrm{U} \cdot \mathrm{A}$ & $\mathrm{U} \cdot \mathrm{A}$ & $\mathrm{U} \cdot \mathrm{A}$ & $\underline{C} \cdot \underline{G}$ & No signature \\
\hline $1244 \cdot 1293$ & $\mathrm{U} \cdot \mathrm{A}$ & $\mathrm{U} \cdot \mathrm{A}$ & $\mathrm{U} \cdot \mathrm{A}$ & $\overline{\mathrm{C}} \cdot \overline{\mathrm{G}}$ & No signature \\
\hline 1304 & $\mathrm{G}$ & G & $\mathbf{A}$ & $\mathrm{G}$ & $\begin{array}{l}\text { A: Hydrogenobacter (2), Fervidobacterium (1), Chloroflexus } \\
\text { subdivision (most), Deinococcus, Gemmata, STB (few), } \alpha- \\
\text { purple (4), Bdellovibrio, Myxobacteria (most), Gr }+(12)\end{array}$ \\
\hline $1421 \cdot 1479$ & $\mathrm{U} \cdot \mathrm{G}$ & $\mathrm{C} \rrbracket \cdot \mathrm{G}$ & $\mathrm{U} \cdot \mathrm{G}$ & $\mathrm{U} \cdot \mathrm{G}$ & $\begin{array}{l}\text { C: TOR (most), FCB (many), Leptospirillum group (2), } \\
\text { Ectothiorhodospira assemblage, Myxobacteria }\end{array}$ \\
\hline $1423 \cdot 1477$ & $A \cdot U$ & $\mathrm{~A} \cdot \mathrm{U}$ & $\begin{array}{l}\mathrm{A} \cdot \mathrm{U} \\
\mathrm{A} \cdot \mathrm{C}\end{array}$ & $\underline{G} \cdot \mathrm{C}$ & No signature \\
\hline $1425 \cdot 1475$ & $\mathrm{C} \cdot \mathrm{G}$ & $\mathrm{U} \cdot \mathrm{G}$ & $\begin{array}{l}\mathrm{U} \cdot \mathrm{G} \\
\mathrm{U} \cdot \mathrm{C}\end{array}$ & $\mathrm{U} \cdot \mathrm{G}$ & $\begin{array}{l}\text { C: Sporomusa sub-group (most), Cyanobacteria (some), } \\
\text { Ehrlichia (2), Arcobacter (3) }\end{array}$ \\
\hline $1426 \cdot 1474$ & $\underline{\mathrm{U}} \cdot \underline{\mathrm{G}}$ & $\mathrm{G} \cdot \mathrm{U}$ & $\mathrm{G} \cdot \mathrm{U}$ & $\mathrm{G} \cdot \mathrm{U}$ & No signature \\
\hline $1439 \cdot 1462$ & $\begin{array}{c}\underline{\mathrm{U}} \cdot \overline{\mathbf{A}}, \overline{\mathrm{G}} \cdot \mathrm{C}: \\
M . \text { ovis }\end{array}$ & $\mathrm{G} \cdot \mathrm{C}$ & $\begin{array}{l}\mathrm{A} \cdot \mathrm{U} \\
\mathrm{G} \cdot \mathrm{C}: \\
\mathrm{M} \cdot \text { phe }\end{array}$ & $\begin{array}{l}\mathrm{C} \cdot \mathrm{G} \\
\mathrm{G} \cdot \mathrm{C}\end{array}$ & $\begin{array}{l}\text { A: TOR (most), Simkania, Cyanobacteria (some), } \\
\text { Leptospira group, Burkholderia sub-group I, Bordetella } \\
\text { sub-group, Rubrivivax sub-group, Rhodocyclus, Halomonas } \\
\text { group (most), Campylobacter (some), Mycoplasma } \\
\text { pneumoniae group (some), other Gr }+(7)\end{array}$ \\
\hline
\end{tabular}

* Nucleotide positions are according to the E. coli numbering (4).

$\dagger$ The number of sequences in which the actual residue is found is shown in parentheses. Exceptions are listed for signature residues only. Groups and sub-groups are according to the nomenclature used by the Ribosomal Database Project (RDP) (37). Abbreviations: FCB, Flexibacter-Cytophaga-Bacteroides phylum; STB, Spirochaeta-Treponema-Borrelia subdivision; $\alpha$ and $\beta$, alpha and beta subdivision of the purple bacteria (Proteobacteria); TOR, thermophilic oxygen reducers; $\mathrm{Gr}$ - and $\mathrm{Gr}+, \mathrm{Gram}-\mathrm{negative}$ and Grampositive (eu)bacteria.

$\ddagger$ Many (eu)bacteria truncate this region. Parentheses denote that this position is missing in $E$. coli and the number indicates the adjacent position which is present in the $16 \mathrm{~S}$ rRNA sequence of $E$. coli.

$\S$ Comparison restricted to Proteobacteria.

\| This might be a non-basepairing position in the 16S rRNA molecule of the classical Moraxella.

T Comparison restricted to Gram-negative (eu)bacteria.

tide starting at position 184, UCUTACGAGA, in the vicinity of the tetra-nucleotide loop starting at position 187 of the variable region V2 (21) of the 16 S rRNA molecule. This potential probe has four unique nucleotides (bold) and will detect only strains of the $M$. lacunata cluster and distinguish them from all other strains of group I except for Moraxella sp. strain CCUG 27179, which also shares this oligonucleotide sequence. The probe will be evaluated elsewhere.

\section{The $M$. nonliquefaciens cluster}

$M$. nonliquefaciens strains overall showed a high interstrain similarity ( $\geqslant 99.8 \%$ ) on the $16 \mathrm{~S}$ rRNA level (Table 6). Nevertheless, only 2 out of 10 strains shared their exact 16S rRNA sequences with another strain of this species, indicating a certain heterogeneity. A phylogenetic tree was constructed including all $M$. nonliquefaciens strains sequenced in this study. No formation of subclusters was observed as determined from bootstrap values and single nucleotide analysis (data not shown). Therefore, $M$. nonliquefaciens was only represented by the two strains, NCTC 7784 and B2000 (Fig. 2). Two nucleotide positions in the $M$. nonliquefaciens $16 \mathrm{~S}$ rRNA gene can be utilized for diagnostic purposes as they are only shared with $M$. catarrhalis. These residues are situated at positions 669 (G) and 737 (C). Since $M$. nonliquefaciens is so closely related to $M$. lacunata and both species colonize similar habitats in humans, rapid and reliable methods for the detection and differentiation between these species are needed. Therefore, the informative residues presented for $M$. lacunata and the characteristic nucleotides of $M$. nonliquefaciens could be highly valuable in a PCR or hybridization diagnostic assay based on the $16 \mathrm{~S}$ rRNA gene. Moreover, $M$. nonliquefaciens differs from $M$. lacunata by the oligonucleotide GGGUCUU(C)UUA(G)AAGAC, starting at position 835. The residues present in the differing positions in the $16 \mathrm{~S}$ rRNA molecule of $M$. nonliquefaciens are in bold and 
Table 5. Informative nucleotide positions of the 16S rRNA gene correlated to the phylogenetic clusters of the moraxellae belonging to group I

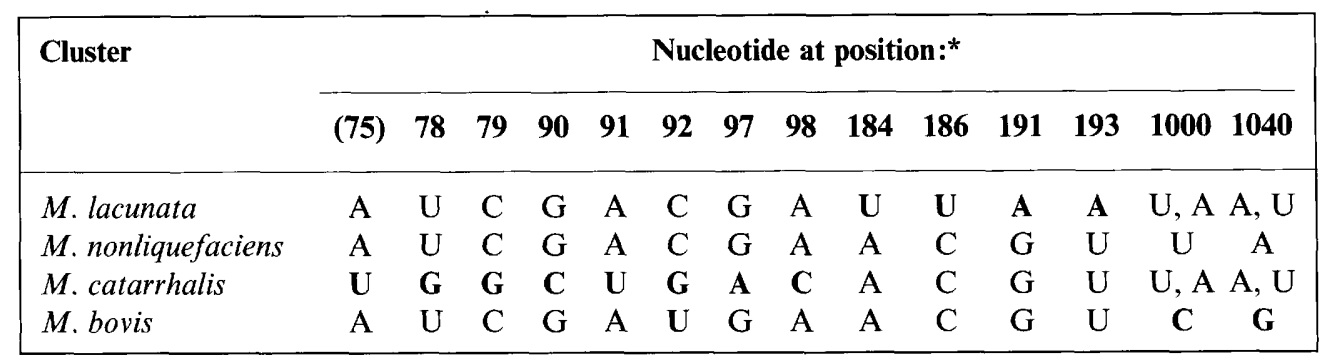

* Nucleotide positions according to the E. coli numbering (4). The strain Moraxella sp. 27179 is excluded (see text for details). Parentheses denote that the corresponding position to that of Moraxella spp. is not present in E. coli. The number within parentheses is the adjacent position in the $E$. coli sequence to that of the actual residue in the $16 \mathrm{~S}$ rRNA sequence of the moraxellae.

those present in the members of the $M$. lacunata cluster are shown in parentheses.

In the maximum likelihood analysis of the members of group I, $M$. nonliquefaciens and $M$. lacunata also formed distinct clusters, but were not positioned at the same branch as in the tree derived by using the neighbour-joining method. The phylogenetic distinctions between these species are supported by genotypic and biochemical properties, such as differences in colony morphology and growth characteristics and the presence of $M$. lacunata serum liquefaction $(5,53)$. We believe that $M$. nonliquefaciens and $M$. lacunata should be placed on the same phylogenetic branch as determined by $16 \mathrm{~S}$ rRNA comparisons (Fig. 2, Table 5). For example, these species share common nucleotide patterns as the $\mathrm{G} \cdot \mathrm{C}, \mathrm{G} \cdot \mathrm{U}$ and $\mathrm{U} \cdot \mathrm{A}$ base pairs in positions $77 \cdot 92,96 \cdot 103$ and $139 \cdot 224$, respectively. They also truncate the U.A base pair at position 76.93 (present in all the other species of group I) of the stem capped by the loop starting in position 83. This truncation constitutes a higher order structural attribute in the 16S rRNA molecule of these species, and is probably a common feature of an apomorphic homologous character.

\section{The $M$. bovis cluster}

The two $M$. bovis strains and the single strain of $M$. ovis formed a cluster, with $M$. ovis branching off from this line of descent (Fig. 2). The 16S rRNA sequences obtained from the two $M$. bovis strains differed from each other by $0.3 \%$. The $16 \mathrm{~S}$ rRNA genes of $M$. bovis and $M$. ovis were $97 \cdot 1-97 \cdot 4 \%$ homologous. This striking similarity clearly shows that $M$. ovis belongs within the genus Moraxella and was previously indicated by results from hybridization (52) and transformation (34). The $M$. bovis cluster constituted an unstable clade due to a low bootstrap percentage value (Fig. 2) and the fact that its phylogenetic significance could only be supported by three informative nucleotide positions, namely $92(\mathrm{U}), 1000(\mathrm{C})$ and $1040(\mathrm{G})$ (Table 5). Additional strains from M. bovis and M. ovis should be analysed to evaluate whether this cluster constitutes a true phylogenetic lineage.

\section{The $M$. catarrhalis cluster}

$M$. catarrhalis, $M$. caviae and $M$. cuniculi represented by four strains clustered together in all trees, however with low bootstrap values, indicating that this cluster might not be stable if more species of group I are subjected to phylogenetic analysis. We found that the strain CCUG 24965, previously classified as $M$. cuniculi, should be assigned as a strain of the species $M$. caviae, since it had a $16 \mathrm{~S}$ rRNA nucleotide sequence identical to that of $M$. caviae strain $355^{\mathrm{T}}$. The lack of affinity of the coccal $M$. ovis to $M$. catarrhalis, $M$. caviae and $M$. cuniculi was evident.

Strikingly, $M$. catarrhalis and $M$. caviae in this cluster shared the composition of $5 \mathrm{bp}$ with $M$. bovis, $M$. nonliquefaciens and the $M$. lacunata subsp. lacunata (including strain E7992) in the vicinity of the tetraloop starting at position 1013. However, the removal of these nucleotides from the alignment, since they might contribute to the destabilization of the node of the $M$. catarrhalis cluster, revealed an identical tree topology to that in Fig. 2 without a substantial improvement of the bootstrap value of the actual node. This cluster can also be justified by eight informative nucleotide positions (Table 5) and by the idiosyncrasy (a truncation of one nucleotide) in a position between 75 and 76 (E. coli lacks this position) of the 16S rRNA molecule. Therefore, the oligonucleotide GUUAGGRAGCUUGCUYCUGAUACYUA surrounding the tetra-loop (underlined) starting at position 83 , constitutes a target of the $16 \mathrm{~S}$ rRNA molecule for identification of the $M$. catarrhalis cluster.

Our results show that $M$. catarrhalis, $M$. caviae and $M$. cuniculi group together and support these coccal species being taxonomically judged as members of the genus Moraxella, forming a phylogenetic cluster within group I $(6,24,56)$, or alternatively as a new genus within Moraxellaceae. 


\section{The Moraxella sp. strain CCUG 27179}

A fifth branch was formed by the strain CCUG 27179, which previously was classified as $M$. cuniculi. However, this could not be regarded as a strain of $M$. cuniculi since it only showed a $95.7 \%$ similarity with the 16S rRNA sequence of the type strain CCUG $2154^{\mathrm{T}}$ of $M$. cuniculi. Strain CCUG 27179 branched early from the line of the $M$. nonliquefaciens and $M$. lacunata clusters in the dendrogram constructed by the neighbour-joining method (Fig. 2). Since strain CCUG 27179 formed the earliest branch of group I when the maximum likelihood method was used for phylogenetic inference (not shown), the phylognetic position of this strain could not be solved in this study.

\section{General group I considerations}

Except for the case in $M$. nonliquefaciens and $M$. lacunata subsp. lacunata, group I was generally highly heterogeneous as seen from the bootstrap values obtained by $16 \mathrm{~S}$ rDNA analysis (Fig. 2) and the branching order between the clusters and between the members within the clusters could not be fully established. A careful check of the variable positions within the alignment revealed that certain nucleotide positions were common to species occupying different clusters of the phylogenetic tree. Moreover, as discussed for the $M$. catarrhalis cluster, some segments appeared to have been shuffled between species which phylogenetically belong to different clusters. These segments and the extent of their occurrence deserve further investigation. Almost $80 \%$ of the variable positions (i.e. 98 out 123 positions) were found to be positioned in highly variable locales of the molecule (21). This means that the trees are derived from nucleotide information present in regions which are prone to mutation. Therefore, it is likely that a certain 'noise' has been incorporated into the phylogenetic analysis: the tree in Fig. 2 should be regarded as tentative and Table 5 might need some revision when 16S rRNA sequence data from more strains and species of group I have been sequenced. Nevertheless, we believe that the five tentative clusters of group I and Table 5 constitute a valuable guide in the future taxonomic and diagnostic work.

In spite of the heterogeneity detected, a relatively high similarity was observed between the species within group I. Typically, the similarity values ranged from 95 to $98.8 \%$, except for that between the $M$. lacunata strains and $M$. equi which were $99.0-99.8 \%$. Thus, the similarity values lie in the range $95-97 \%$, which has been suggested as a general cut-off for species definition within a genus (16). On the other hand, DNADNA reassociation experiments may, however, motivate a classification into new species regardless of high $16 \mathrm{~S}$ rRNA sequence similarities $(20,50)$.

A taxonomic challenge is to decipher whether the entities within the classical moraxellae, namely $M$. nonliquefaciens, $M$. lacunata and $M$. bovis, should represent different species, or whether they should be considered as sub-groups or genovars within one species, exhibiting various biochemical and growth requirements, as well as different habitats. This is one example of how problematic it still is to give strains that appear to be intermediate between known species the optimal designation. When analysed by $16 \mathrm{~S}$ rDNA sequencing, the classical moraxellae and the coccal moraxellae appeared as five major clusters, representing $M$. lacunata, $M$. nonliquefaciens, $M$. bovis, the coccal moraxellae and one unspecified Moraxella sp. Previous DNA-DNA hybridization with total genomic probes gave insufficient distinction for identification purposes between the three closely related species, $M$. nonliquefaciens, $M$. lacunata and $M$. bovis, in spite of their A + T-rich DNAs $(52,53)$. Another challenge is to determine whether the sub-groups present within $M$. lacunata require more distinctive nomenclature. If so, should these (sub)species correspond to what was previously designated as $M$. liquefaciens and $M$. lacunata, or the $M$. lacunata group I and group II strains $(34,53)$ ? The clustering in these groups by $16 \mathrm{~S}$ rDNA analysis appeared to correspond well to the two sets of $M$. lacunata strains found by cell wall fatty acid patterns, as well as to hybridization analysis (53) and the two donor transformation activities towards $M$. bovis (34). The difference between the $M$. lacunata groups was so marked, that although they are mutually more closely related than to the other moraxellae, they are so distinct that the previous species distinctions of $M$. lacunata and $M$. liquefaciens (5) should be reconsidered.

In medical microbiology, the distinction between strains of $M$. catarrhalis, $M$. nonliquefaciens and $M$. lacunata is most relevant, as these species colonize similar habitats in humans. $M$. catarrhalis is easily recognized by its characteristic growth pattern and ease in agar surface sliding (12). Serum liquefaction and growth requirements $(5,31)$ are traits that may help distinguish $M$. nonliquefaciens and $M$. lacunata, but such tests are often not employed in ordinary routine diagnostic work and their value as specific key reactions is not fully exploited. Separation between the two species has previously been demonstrated by genetic transformation $(5,31)$, but the laborious quantitative assay needed for this fine distinction is time-consuming and dependent on competent strains. The target regions of the $16 \mathrm{~S}$ rRNA molecule outlined in this paper will be of importance in the development of new PCR-based diagnostic tools for these species.

Distinction between $M$. lacunata and $M$. bovis can usually be obtained easily by the expression of haemolysis of $M$. bovis as well as by difference in habitat $(9,34)$. A problem in this context are non-haemolytic strains of $M$. bovis, as well as the non-haemolytic entity $M$. equi, found in horses $(5,34)$. This type of taxonomical problem is likely to be more pronounced when a wider environment is investigated for the presence of strains of group I, as already shown by Kodjo and co-workers (35). 


\section{Group II, including $\boldsymbol{M}$. osloensis and $\boldsymbol{M}$. atlantae}

Group II comprised only the two species $M$. osloensis strain 5873 and $M$. atlantae strain 1922 which formed a common and distinct clade (Fig. 1, Table 4) in all derived phylogenies. A partial 16S rRNA sequence consisting of 729 nucleotides could be retrieved for the type strain ATCC $19976^{T}$ of M. osloensis (17) to which strain 5873 showed only a few nucleotide differences. A tree was constructed from a data set consisting of only partial $16 \mathrm{~S}$ rRNA sequences and the two $M$. osloensis strains clustered tightly together (tree not shown). The strains of $M$. osloensis and $M$. atlantae were only distantly related to each other, displaying a $93.4 \%$ nucleotide similarity between their $16 \mathrm{~S}$ rRNA genes and $\leqslant 93 \%$ to the other members of the Moraxellaceae family including the moraxellae of group I.

$\boldsymbol{M}$. osloensis. The systematic work regarding the taxonomic position of $M$. osloensis has been extensively investigated by genotypic and phenotypic studies (10, $17,30,46,54)$. However, the placement of this species has remained uncertain. The last taxonomic effort led to the proposal to classify $M$. osloensis in the $M$. lacunata rRNA homology group (46). We searched the $16 \mathrm{~S}$ rRNA sequences through for unique nucleotide positions which were shared between $M$. osloensis and all members of group I of Moraxellaceae. Only two positions were found, namely the residues at position $453(\mathrm{G})$ and $861(\mathrm{U})$. Interestingly, only two positions were also found to be shared between the strain of $M$. atlantae and the $M$. lacunata rRNA homology group. These positions were 1355 (A) and 1367 (U). Moreover, an additional thymidine residue was found situated between positions 649 and 650 in the $16 \mathrm{~S}$ rRNA gene of both $M$. osloensis strains. This structural element was not present in any other member of the Moraxellaceae and was rarely found among other (eu)bacteria. The resulting $U$ constitutes a unilaterally bulged residue in the actual locale of the matured $16 \mathrm{~S}$ rRNA molecule and is a higher-order structural idiosyncrasy for the species $M$. osloensis. Thus, our analysis showed that there is no evidence on the $16 \mathrm{~S}$ rRNA level to include $M$. osloensis in group I. Also, there are other properties which support a definitive exclusion of $M$. osloensis as a member of the $M$. lacunata rRNA homology group (group I), such as its distinct fatty acid profile and findings by genetic transformation $(9,10,30)$. This is the only bacterium with pronounced formation of fusiform cells when cultured at sublethal concentrations of penicillin.

M. atlantae. The strain of $M$. atlantae had easily the longest single branch in this part of the phylogenetic tree. One can speculate whether this species has a significantly higher evolutionary rate. However, more strains of $M$. atlantae have to be sequenced to allow clarification of whether the long branch is due to phylogenetic information or to phylogenetic noise, resulting in a long-branch artifact (18). $M$. atlantae shares characteristics, such as the cellular lipid com- position which resembles that of $[M$.$] phenylpyruvica,$ but $M$. atlantae differs from $[M$.] phenylpyruvica by containing true waxes $(8,9)$. Also, $M$. atlantae grows with particularly small colonies which display highly fimbriated phenotypes by virtue of its colony morphology and pronounced twitching motility.

\section{Group III, including [M.] phenylpyruvica 752/52 and the genus Psychrobacter}

Group III included a single Moraxella strain, namely [M.] phenylpyruvica strain 752/52 (11), which was sequenced in this work, and the genus Psychrobacter recently investigated by Bowman et al. (2). The group III line of descent was regarded reliable as judged from the consistency measures (Fig. 1, Table 4). The members of the Psychrobacter-[M.] phenylpyruvica group were only distantly related to the species of the other three groups of the Moraxellaceae family, with a $16 \mathrm{~S}$ rRNA sequence similarity $\leqslant 93 \cdot 1 \%$.

[M.] phenylpyruvica. [M.] phenylpyruvica strain $752 / 52$ (different from ATCC $23333^{\mathrm{T}}$ ) was found to be positioned early on the same branch as the Psychrobacter strains in all inferred phylogenic trees (represented by Fig. 1). Interestingly, the $[M$. $]$ phenylpyruvica strain $752 / 52$ revealed a $16 \mathrm{~S}$ rRNA sequence similarity of only $95.9 \%$ with the recently established Psychrobacter phenylpyruvicus type strain which indicated that $752 / 52$ is not a strain of this species (which hosts the previous type strain ATCC $23333^{\mathrm{T}}$ of $M$. phenylpyruvica) $(2,11)$. Moreover, strain $752 / 52$ was found to be only distantly related to the other members of the Moraxellaceae due to a 16S rRNA sequence similarity value of $\leqslant 93.1 \%$. In comparison, strain $752 / 52$ showed a significantly higher $16 \mathrm{~S}$ rRNA sequence similarity value $(\geqslant 94.6 \%)$ to the species of genus Psychrobacter, which is still not very high. The group containing Psychrobacter spp. and strain 752/52 has long since been described as both genotypically and phenotypically heterogeneous $(11,31-33,46)$. The genus status of $M$. phenylpyruvica has also been questioned repeatedly $(8,11,46)$.

Studies based on comparison of features other than ribosomal sequence differences also conflict with a classification of $[M$.$] phenylpyruvica strain 752 / 52$ into the genus Moraxella, as well as into the genus Psychrobacter. Strains of $[M$.$] phenylpyruvica are$ usually phenylalanine-deaminase- and urease-positive, and true waxes are absent in the fatty acid profile $(8$, 11). Until now, no naturally competent culture of $[M$.] phenylpyruvica strain $752 / 52$ has been found. The complete lack of transforming activity between $[M$.] phenylpyruvica strain $752 / 52$ as donor DNA and Psychrobacter sp. strongly goes against there being a close affiliation between these entities (33). The 16S rDNA sequence analysis displays this divergence, however to a lesser extent. The branch of $[M$. phenylpyruvica and Psychrobacter spp. is characterized by several common signature and unique $16 \mathrm{~S}$ rRNA residues (Table 4), but one difference is noteworthy. In 
position 1336 , the $16 \mathrm{~S}$ rRNA gene of $[M$. phenylpyruvica] has a cytosine residue, while Psychrobacter sp. displays an adenine residue, representing a signature for the latter species. The results from this study suggest that $[M$.] phenylpyruvica strain $752 / 52$ is neither a species of the genus Moraxella nor a member of Psychrobacter, and that it should be placed in a new genus.

\section{Group IV, including the genus Acinetobacter sensu stricto}

This group we only analysed by means of pre-exisiting 16S rDNA sequences from the databases. Group IV consisted solely of species belonging to the genus Acinetobacter, represented by a strain of $A$. calcoaceticus. The phylogenetic relation among the Acinetobacter species has been published previously $(1,44,55$, 59) and was not focused on in this work. The genus Acinetobacter formed an early branch of the Moraxellaceae family in all constructed trees (Fig. 1). Binary similarity values between members of Acinetobacter and groups I-III ranged between 86 and $90 \%$. In general, group IV showed the slightly higher $16 \mathrm{~S}$ rRNA sequence similarity percentage value to group I (the $M$. lacunata rRNA homology group). Despite the phylogenetic proximity exhibited among different species of Acinetobacter on the 16S rRNA level (44), studies on the total genome level have demonstrated that species of the genus Acinetobacter are very heterogeneous, to such an extent that some Acinetobacter species show very low DNA reassociation values, indicating that they should be placed in separate genera (51).

\section{Overall nucleotide distribution and variability between Moraxella species on the 16S rDNA level}

Higher diversity was found on the 16S rDNA level among the Moraxella species than could be expected based on phenotypic similarities, on overall nucleic acid homologies by hybridization and on ratios in genetic transformation. Considering the extensive genetic exchange that goes on in nature among these bacteria, due to their naturally high competence for constitutive transformation throughout their life-cycle combined with a target that could be subject to homologous recombination with DNA from a vast amount of bacterial species, a relatively high diversity on the 16S rDNA sequence level is not unlikely. Compared to species that exhibit particularly high conservation on the 16S rDNA sequence level, such as the Mycobacteria, strains of species of Moraxellacae contain relatively high $16 \mathrm{~S}$ rDNA sequence divergence. This finding promotes the use of $16 \mathrm{~S}$ rDNA sequence analysis for fine discrimination between strains and entities, but limits its use for species discrimination of this bacterial family.

\section{Concluding remarks}

We believe that the 16S rRNA gene sequences from strains of the type genus Moraxella determined and discussed in this work constitute an important part of the framework for taxonomic studies of the members of the family Moraxellaceae. Taxonomic realignment of genera and species within the Moraxellaceae is not proposed in this report. The analysis of additional strains within each species/entity will be necessary to obtain a more finite classification and complete phylogenetic status of this family. Areas of interest deserving the highest priority in this pursuit are the genus Moraxella sensu stricto and the genus Psychrobacter and allied bacteria. Moreover, nucleotide sequence data of the 16S rRNA genes from members of both groups II and III are needed for proper taxonomic affiliation of $M$. osloensis, $M$. atlantae, [M.] phenylpyruvica and related species within these groups.

\section{ACKNOWLEDGEMENTS}

We thank K. Bøvre, E. Juni and E. Stackebrandt for inspiring discussions and constructive comments on this manuscript. This work was supported by grants from the Anders Jahres Foundation and the Norwegian Research Council to T.T. and from the Göran Gustafsson Foundation and the Swedish Engineering Science Research Council to M.U.

\section{REFERENCES}

1. Bouvet, P. J. M. \& Grimont, P. A. D. (1986). Taxonomy of the genus Acinetobacter with the recognition of Acinetobacter baumani sp. nov., Acinetobacter haemolyticus sp. nov., Acinetobacter johnsonii sp. nov., and Acinetobacter junii sp. nov., and emended descriptions of Acinetobacter calcoaceticus, and Acinetobacter lwoffi. Int J Syst Bacteriol 36, 228-240.

2. Bowman, J. P., Cavanagh, J., Austin, J. Y. \& Sanderson, K. (1996). Novel Psychrobacter species from antarctic ornithogenic soils. Int $J$ Syst Bacteriol 46, 841-848.

3. Brorson, J. E., Falsen, E., Ehle-Nilsson, H., Rodjer, S. \& Westin, J. (1983). Septicemia due to Moraxella nonliquefaciens in a patient with multiple myeloma. Scand $J$ Infect Dis $\mathbf{1 5}$, 221-223.

4. Brosius, J., Palmer, J. L., Kennedy, J. P. \& Noller, H. F. (1978). Complete nucleotide sequence of a $16 \mathrm{~S}$ ribosomal RNA gene from Escherichia coli. Proc Natl Acad Sci USA 75, 4801-4805.

5. Bøvre, K. (1965). Studies on transformation in Moraxella and organisms assumed to be related to Moraxella. 5. Streptomycin resistance transformation between serumliquefying, nonhaemolytic moraxellae, Moraxella bovis and Moraxella nonliquefaciens. Acta Pathol Microbiol Scand 45 , 435-449.

6. Bøvre, K. (1979). Proposal to divide the genus Moraxella Lwoff 1939 emend. Henriksen and Bøvre 1968 into two subgenera, subgenus Moraxella (Lwoff 1939) Bøvre 1979 and subgenus Branhamella (Catlin 1970) Bøvre 1979. Int J Syst Bacteriol 29, 403-406.

7. Bøvre, K. (1984). Genus II. Moraxella Lwoff 1939, 173 emend. Henriksen and Bøvre 1968, 391 ${ }^{\mathrm{AL}}$. In Bergey's 
Manual of Systematic Bacteriology, vol. 1, pp. 2297-2303. Edited by N. R. Krieg \& J. B. Holt. Baltimore: Williams \& Wilkins.

8. Bøvre, K., Fuglesang, J. E., Hagen, N., Jantzen, E. \& Frøholm, L. O. (1976). Moraxella atlantae sp. nov, and its distinction from Moraxella phenylpyruvica. Int J Syst Bacteriol 26, 511-521.

9. Bøvre, K. \& Hagen, N. (1980). The family Neisseriaceae: rodshaped species of the genera Moraxella, Acinetobacter, Kingella, and Neisseria, and the Branhamella group of cocci. In The Prokaryotes: a Handbook on Habitats, Isolation, and Identification of Bacteria, vol. 2, pp. 1506-1529. Edited by M. P. Starr, H. Stolp, H. G. Trüper, A. Balows \& H. G. Schlegel. Berlin: Springer.

10. Bøvre, K. \& Henriksen, S. D. (1967). A new Moraxella species, Moraxella osloensis, and a revised description of Moraxella nonliquefaciens. Int J Syst Bacteriol 17, 127-135.

11. Bøvre, K. \& Henriksen, S. D. (1967). A revised description of Moraxella polymorpha Flamm 1957, with a proposal of a new name, Moraxella phenylpyruvica, for this species. Int $J$ Syst Bacteriol 17, 343-360.

12. Catlin, B. W. (1964). Reciprocal genetic transformation between Neisseria catarrhalis and Moraxella nonliquefaciens. J Gen Microbiol 37, 369-379.

13. Catlin, B. W. (1970). Transfer of the organism named Neisseria catarrhalis to Branhamella gen. nov. Int J Syst Bacteriol 20, 155-159.

14. Catlin, B. W. (1990). Branhamella catarrhalis: an organism gaining respect as a pathogen. Clin Microbiol Rev 3, 293-320.

15. Catlin, B. W. (1991). Branhamaceae fam. nov., a new bacterial family to accomodate the genera Branhamella and Moraxella. Int J Syst Bacteriol 41, 320-323.

16. Dewhirst, F. E., Paster, B. J., La Fontaine, S. \& Rood, J. I. (1990). Transfer of Kingella indologenes (Snell and Lapage 1976) to the genus Suttonella gen. nov. as Suttonella indologenes comb. nov.; transfer of Bacteroides nodosus (Beveridge 1941) to the genus Dichelobacter gen. nov. as Dichelobacter nodosus comb. nov.; and assignment of the genera Cardiobacterium, Dichelobacter, and Suttonella to Cardiobacteriaceae fam. nov. in the gamma division of Proteobacteria on the basis of $16 \mathrm{~S}$ rRNA sequence comparisons. Int J Syst Bacteriol 40, 426-433.

17. Enright, M. C., Carter, P. E., MacLean, I. A. \& McKenzie, H. (1994). Phylogenetic relationships between some members of the genera Neisseria, Acinetobacter, Moraxella, and Kingella based on partial 16S ribosomal DNA sequence analysis. Int $J$ Syst Bacteriol 44, 387-391.

18. Felsenstein, J. (1978). Cases in which parsimony or compatibility methods will be positively misleading. Syst Zool 27, 401-410.

19. Felsenstein, J. (1993). PHYLIP: phylogeny inference package (version $3.51 \mathrm{c}$ ). Department of Genetics, University of Washington, Seattle.

20. Fox, G. E., Wisotzkey, J. D. \& Jurtshuk, P., Jr (1992). How close is close: 16S rRNA sequence identity may not be sufficient to guarantee species identity. Int J Syst Bacteriol 42, 166-170

21. Gray, M. W., Sankoff, D. \& Cedergren, R. J. (1984). On the evolutionary descent of organisms and organelles: a global phylogeny based on a highly conserved structural core in small subunit ribosomal RNA. Nucleic Acids Res 12, $5837-5852$
22. Gutell, R. R. (1994). Collection of small (16S- and 16S-like) ribosomal RNA structures: 1994. Nucleic Acids Res 22, 3502-3507.

23. Henriksen, S. D. (1969). Proposal of a neotype strain for Moraxella lacunata. Int J Syst Bacteriol 19, 263-265.

24. Henriksen, S. D. \& Bøvre, K. (1968). The taxonomy of the genera Moraxella and Neisseria. J Gen Microbiol 51, 387-392.

25. Hughes, D. E. \& Pugh, G. W., Jr (1970). A five-year study of bovine infectious keratoconjunctivitis in a beef herd. $J \mathrm{Am}$ Vet Med Assoc 157, 443-454.

26. Hultman, T., Bergh, S., Moks, T. \& Uhlén, M. (1991). Bidirectional solid phase sequencing of in vitro-amplified plasmid DNA. BioTechniques 10, 84-93.

27. Hultman, T., Ståhl, S., Hornes, E. \& Uhlén, M. (1989). Direct solid phase sequencing of genomic and plasmid DNA using magnetic beads as solid support. Nucleic Acids Res 17, $4937-4946$.

28. Jukes, T. H. \& Cantor, C. R. (1969). Evolution of protein molecules. In Mammalian Protein Metabolism, vol. 3, pp. 21-132. Edited by H. N. Munro. New York: Academic Press.

29. Juni, E. (1972). Interspecies transformation of Acinetobacter: genetic evidence for a ubiquitous species. $J$ Bacteriol 112, 917-931.

30. Juni, E. (1974). Simple genetic transformation assay for rapid diagnosis of Moraxella osloensis. Appl Microbiol 27, $16-24$.

31. Juni, E. (1991). The genus Psychrobacter. In The Prokaryotes, pp. 3241-3246. Edited by A. Balows, H. G. Trüper, M. Dworkin, W. Harder \& K.-H. Schleifer. New York: Springer.

32. Juni, E. \& Heym, G. A. (1980). Transformation assays for identification of psychrotrophic achromobacters. Appl Environ Microbiol 40, 1106-1114.

33. Juni, E. \& Heym, G. A. (1986). Psychrobacter immobilis gen. nov.: genospecies composed of Gram-negative, aerobic oxidase-positive coccobacilli. Int J Syst Bacteriol 36, 388391.

34. Juni, E., Heym, G. A. \& Newcomb, R. D. (1988). Identification of Moraxella bovis by qualitative genetic transformation and nutritional assays. Appl Environ Microbiol 54, 1304 1306.

35. Kodjo, A., Tønjum, T., Richard, Y. \& Bøvre, K. (1995). Moraxella caprae sp.nov., a new member of the classical moraxellae, with very close affinity to Moraxella bovis. Int $J$ Syst Bacteriol 45, 467-471.

36. Lane, D. J., Pace, B., Olsen, G. J., Stahl, D. A., Sogin, M. L. \& Pace, N. R. (1985). Rapid determination of $16 \mathrm{~S}$ ribosomal RNA sequences for phylogenetic analysis. Proc Natl Acad Sci USA 82, 6955-6959.

37. Maidak, B. L., Olsen, G. J., Larsen, N., Overbeek, R., McCaughey, M. J. \& Woese, C. R. (1996). The ribosomal database project (RDP). Nucleic Acids Res 24, 82-85.

38. Martinez-Murcia, A. J., Benlloch, S. \& Collins, M. D. (1992). Phylogenetic interrelationships of members of the genera Aeromonas and Plesiomonas as determined by $16 \mathrm{~S}$ ribosomal DNA sequencing: lack of congruence with results of DNA-DNA hybridizations. Int J Syst Bacteriol 42, 412421.

39. Olsen, G. J. \& Woese, C. R. (1993). Ribosomal RNA : a key to phylogeny. FASEB J 7, 113-123. 
40. Pettersson, B., Johansson, K.-E. \& Uhlén, M. (1994). Sequence analysis of $16 \mathrm{~S}$ rRNA from mycoplasmas by direct solid phase DNA sequencing. Appl Environ Microbiol 60, 24562461 .

41. Pettersson, B., Leitner, T., Ronaghi, M., Bölske, G., Uhlén, M. \& Johansson, K.-E. (1996). The phylogeny of the Mycoplasma mycoides cluster as determined by sequence analysis of the 16S rRNA genes from the two rRNA operons. $J$ Bacteriol 178, 4131-4142.

42. Pettersson, B., Lembke, F., Hammer, P., Stackebrandt, E. \& Priest, F. G. (1996). Bacillus sporothermodurans, a new species producing highly heat-resistant endospores. Int $J$ Syst Bacteriol 46, 759-764.

43. Pettersson, B., Uhlén, M. \& Johansson, K.-E. (1996). The phylogeny of some ruminant mycoplasmas based on $16 \mathrm{~S}$ rRNA sequences and definition of a new cluster within the hominis group. Int J Syst Bacteriol 46, 1093-1098.

44. Rainey, F. A., Lang, E. \& Stackebrandt, E. (1994). The phylogenetic structure of the genus Acinetobacter. FEMS Microbiol Lett 124, 349-354.

45. Ringvold, A., Vik, E. \& Bevanger, L. S. (1985). Moraxella lacunata isolated from epidemic conjunctivitis among teenaged females. Acta Ophthalmol 63, 427-431.

46. Rossau, R., Van Landschoot, A., Gillis, M. \& De Ley, J. (1991). Taxonomy of Moraxellaceae fam. nov., a new bacterial family to accomodate the genera Moraxella, Acinetobacter, and Psychrobacter and related organisms. Int $J$ Syst Bacteriol 41, 310-319.

47. Saitou, N. \& Nei, M. (1987). The neighbor-joining method: a new method for reconstructing phylogenetic trees. Mol Biol Evol 4, 406-425.

48. Stackebrandt, E. (1988). Phylogenetic relationships vs. phenotypic diversity: how to achieve a phylogenetic classification system of the eubacteria. Can $J$ Microbiol 34, $552-556$.

49. Stackebrandt, E., Murray, R. G. E. \& Trüper, H. G. (1988). Proteobacteria classis nov., a name for the phylogenetic taxon that includes the "purple bacteria" and their relatives. Int J Syst Bacteriol 38, 321-325.
50. Stackebrandt, E. \& Goebel, B. M. (1994). Taxonomic note: a place for DNA- DNA reassociation and 16S rRNA sequence analysis in the present definition in bacteriology. Int J Syst Bacteriol 44, 846-849.

51. Towner, K. (1991). The genus Acinetobacter. In The Prokaryotes, vol. 4, pp. 3137-3143. Edited by A. Balows, H. G. Trüper, M. Dworkin, W. Harder \& K.-H. Schleifer. New York: Springer.

52. Tønjum, T., Bukholm, G. \& Bøvre, K. (1989). Differentiation of some species of Neisseriaceae and other bacterial groups by DNA-DNA hybridization. APMIS 97, 395-405.

53. Tønjum, T., Caugant, D. A. \& Bøvre, K. (1992). Differentiation of Moraxella nonliquefaciens, $M$. lacunata and $M$. bovis by multilocus enzyme electrophoresis and hybridization with pilin-specific DNA probes. J Clin Microbiol 30, 3099-3107.

54. Vandamme, P., Gillis, M., Vancanneyt, M., Hoste, B., Kersters, K. \& Falsen, E. (1993). Moraxella lincolnii sp. nov., isolated from the human respiratory tract, and re-evaluation of the taxonomic position of Moraxella osloensis. Int $J$ Syst Bacteriol 43, 474-481.

55. Van Landschoot, A., Rossau, R. \& De Ley, J. (1986). Intra- and intergeneric similarities of the ribosomal ribonucleic acid cistrons of Acinetobacter. Int J Syst Bacteriol 36, 150-160.

56. Veron, M., Lenvoise-Furet, A., Coustere, C., Ged, C. \& Grimont, F. (1993). Relatedness of three species of "false Neisseria", Neisseria caviae, Neisseria cuniculi, and Neisseria ovis by DNA-DNA hybridizations and fatty acid analysis. Int $J$ Syst Bacteriol 43, 210-220.

57. Wahlberg, J., Holmberg, A., Bergh, S., Hultman, T. \& Uhlén, M. (1992). Automated magnetic preparation of DNA templates for solid phase sequencing. Electrophoresis 13, 547-551.

58. Woese, C. R. (1987). Bacterial evolution. Microbiol Rev 51, 221-271.

59. Yamamoto, S. \& Harayama, S. (1996). Phylogenetic analysis of Acinetobacter strains based on the nucleotide sequences of $g y r B$ genes and on the amino acid sequences of their products. Int J Syst Bacteriol 46, 506-511. 